\title{
Debate - The Canadian Association of Gastroenterology should follow the Canadian Medical Association guidelines for maintenance of certification: Agree
}

\author{
Desmond Leddin MB FRCPC
}

A regional gastroenterology group requests the accreditation of a meeting that will provide an update regarding diseases of the gastrointestinal tract. The topics were developed by a committee without industry input and were based on a needs assessment. The speakers were not picked by industry. The expenses of the attendees and their guests will be paid by industry. Families and partners, but not physicians, will be charged a registration fee. The meeting will be held at a well-known resort and the registration will cover part of the expenses.

Under Canadian A ssociation of $G$ astroenterology (CA G ) guidelines, this meeting would not be accredited under the Royal College Maintenance of Certification Program ( $M$ O C ERT). It can be argued convincingly that this format of meeting is no longer acceptable because it is unethical for physicians to accept gifts from industry. Receiving gifts from industry creates a conflict of interest, decreases the credibility of physicians as advocates for patient needs and creates an environment where industry sponsors may influence the educational agenda. It is important to note, however, that no one is saying the meeting cannot take place. Physicians are perfectly free to attend any function they wish. The decision to not accredit the meeting simply means that it will not have the Royal C ollege and CA G seal of approval.

A dditional background to this controversy may be useful. In 2001, the CA G applied to the Royal College to become the designated accreditor of gastroenterology educational events for the M OCERT program. M O CERT was established, in part, to demonstrate to the public and the provincial medical colleges that the profession is capable of meeting its own educational needs. The integrity of this process is critical. Because many educational events are funded by industry, it follows that some rules need to govern the interaction of industry with the education providers. The College did not write its own standards, but adopted those developed by the $C$ anadian $M$ edical A ssociation ( $C M A$ ). As part of the CAG application, the C A G agreed to adopt the CM A ethics guidelines. This proposal was unanimously adopted by the board of the CA G and accepted by the CA G membership at the last annual general meeting in $\mathrm{M}$ ontreal.
The C ode of Ethics of the CM A is available on the Internet at www.cma.ca (1). It consists of two sections; the code itself, which consists of 43 statements, and a second section made up of a number of specific CM A policy statements.

CA G has accredited numerous meetings without difficulty. One issue surfaces repeatedly, however, and has consumed more of the education committee's time than any other. In section 24 of the CMA's policy on Physicians and the Pharmaceutical industry there is the statement that reads, "... the industry sponsor should not pay for travel or lodging costs or for other personal expenses of physicians attending a CME/CPD event" (2). Therefore, the CAG education committee does not accredit a meeting if physician travel and expenses, other than that for speakers, are paid.

The majority of industry sponsors and physician groups have had no difficulty in complying with these new realities. Some industry and physician groups continue to chafe at these restrictions. It is useful to consider why. 0 ne explanation may be that some companies use education events as marketing tools (3). The payment of physicians and physicians' families expenses is a gift. G ift giving is a powerful social act that influences physician behavior. The prohibition of this particular form of gift giving presumably interferes with an effective marketing strategy.

W hy would physicians object? There are the palpable pleasures of expense-free trips to some of the country's best resorts. Some physician groups erroneously regard the decision of the CA G to withhold accreditation as a slight on the educational value of the proposed meeting. In addition, if a regional organization is unable to stage an accredited meeting, it is likely that future attendance and industry funding will decrease.

W hat is the ethical issue? C entral to this debate is the concept of conflict of interest. Conflict of interest has been defined as "a set of conditions in which professional judgment concerning a primary interest tends to be unduly influenced by a secondary interest" (4). The primary responsibility of the physician is to the patient. A ccepting gifts from industry creates a secondary interest, an obligation to the sponsor and a conflict between the physician's responsibilities to the patient and the industry sponsor. 
In addition to the potential damage to the physicianpatient relationship, the development of even an apparent conflict of interest can damage the credibility of physicians with both government and hospital administration. If a physician accepts gifts from the manufacturer of a new product, can the hospital pharmacy, for example, consider the physician's advice unbiased? H ow can government rely on physician in put if we are under an obligation to industry? Perhaps the more serious effect on patient care is not that the physicians may prescribe one drug over another but that we will lose our standing as patient advocates because of our apparent, or even perceived, conflict of interest.

Ethics and the law are not al ways congruent, but they are in this case. Physicians, because of their position of power in their relationships with patients, have both ethical and legal obligations. Physicians have a fiduciary duty to patients (5). Fiduciary duties, from the Latin word meaning trust, are those where one party is entrusted to protect the rights of another, weaker, party. Conflict of interest rules are established in Ontario legal precedents.

The CA G, CMA, and Royal College position is similar to that of other national organizations, including that of the A merican College of Physicians. The A merican College of Physicians has proposed a number of questions that physicians might find useful in deciding whether they should accept gifts from industry $(6,7)$. "W hat would my patients think about this arrangement? W hat would the public think? H ow would I feel if the relationship was disclosed through the media? W hat is the purpose of the industry offer? What would my colleagues think about this arrangement? W hat would I think if my own physician accepted this offer?"

The CMA guidelines are not the problem, but rather the solution to the problem of how to ensure that interactions between physicians and industry are both appropriate and seen to be appropriate. A ccordingly, they deserve our strong support.

\section{REFERENCES:}

1. Code of Ethics of the $C$ anadian M edical A ssociation. <http://www.cma.ca/cma/common/displayPage.do?pagel d=/stati cC ontent/H T M L/N 0//2/inside/policybase/1996/10-15.htm> (Version current as of February 18, 2003)

2. CM A Policy: Physicians and the Pharmaceutical Industry. <http://www.cma.ca/staticC ontent/H T M L/N 0//2/where_we_sta $\mathrm{nd} /$ physicians_and_the_pharmaceutical_industry.pdf $>$ (V ersion current as of February 18, 2003)

3. Rakatansky H. Review article: G astroenterology and the pharmaceutical industry. A liment Pharmacol Ther 2002:16;1859-66.

4. Thompson DF. U nderstanding financial conflicts of interest. N Engl J M ed 1993;329:573-6.

5. Singer PA (ed). Bioethics at the Bedside. A Clinician's G uide. CMA Publications, 1999.

6. Coyle SL. Physician - Industry relations. Part 1: Individual physicians. A nn Intern M ed 2002;135:396-402.

7. Coyle SL. Physician - Industry relations. Part 2: O rganizational Issues. A nn Intern M ed 2002;135:403-6. 


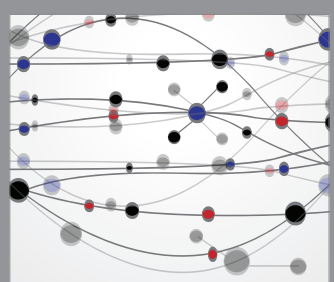

The Scientific World Journal
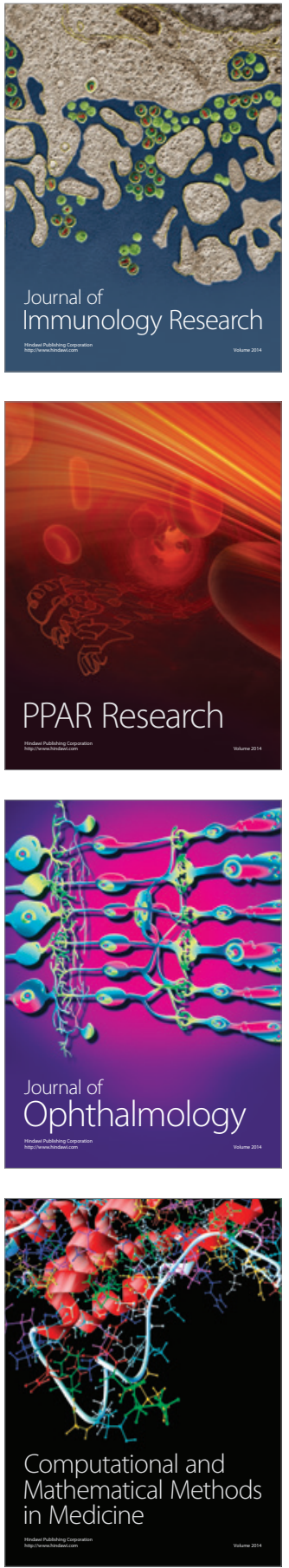

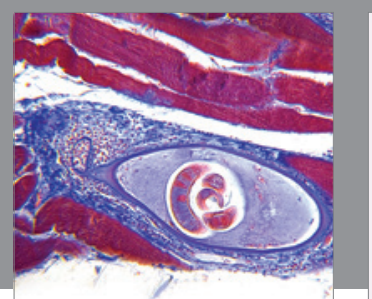

Gastroenterology Research and Practice

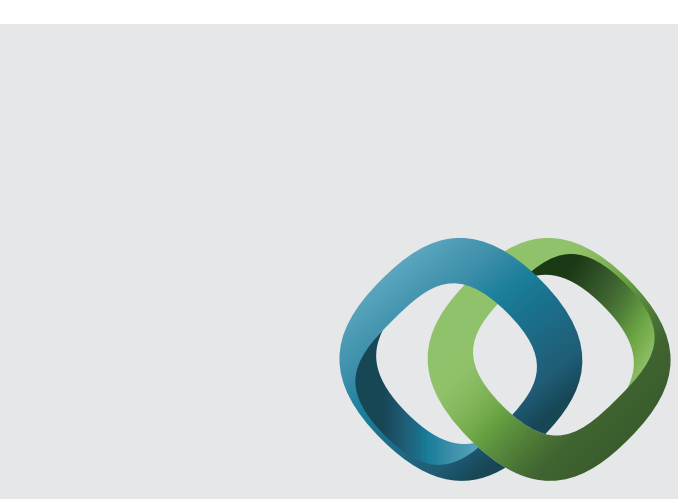

\section{Hindawi}

Submit your manuscripts at

http://www.hindawi.com
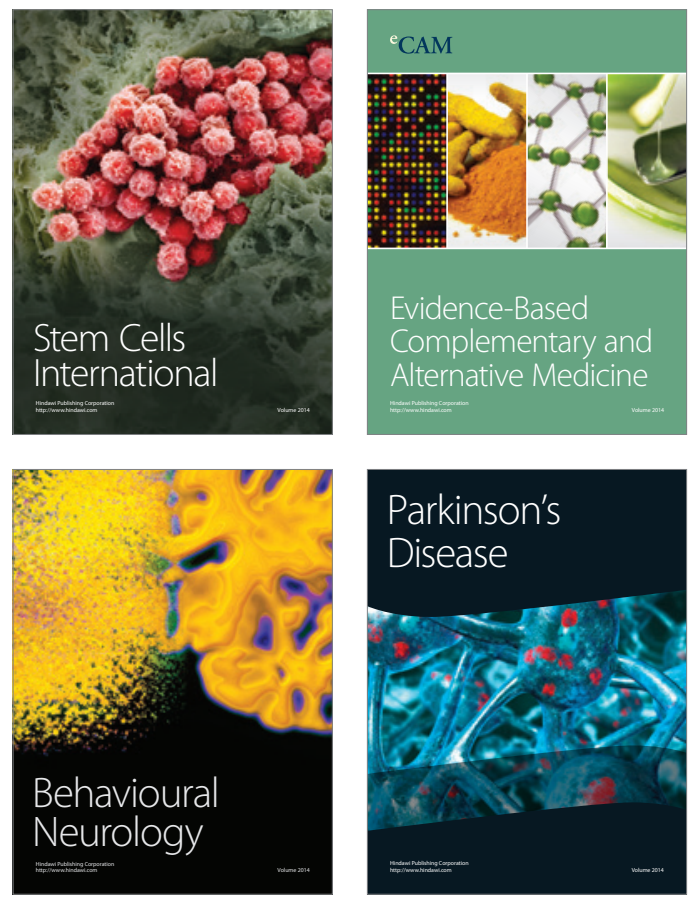
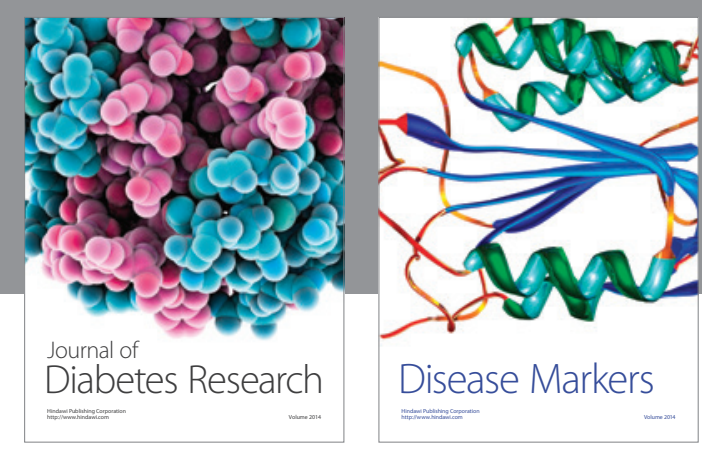

Disease Markers
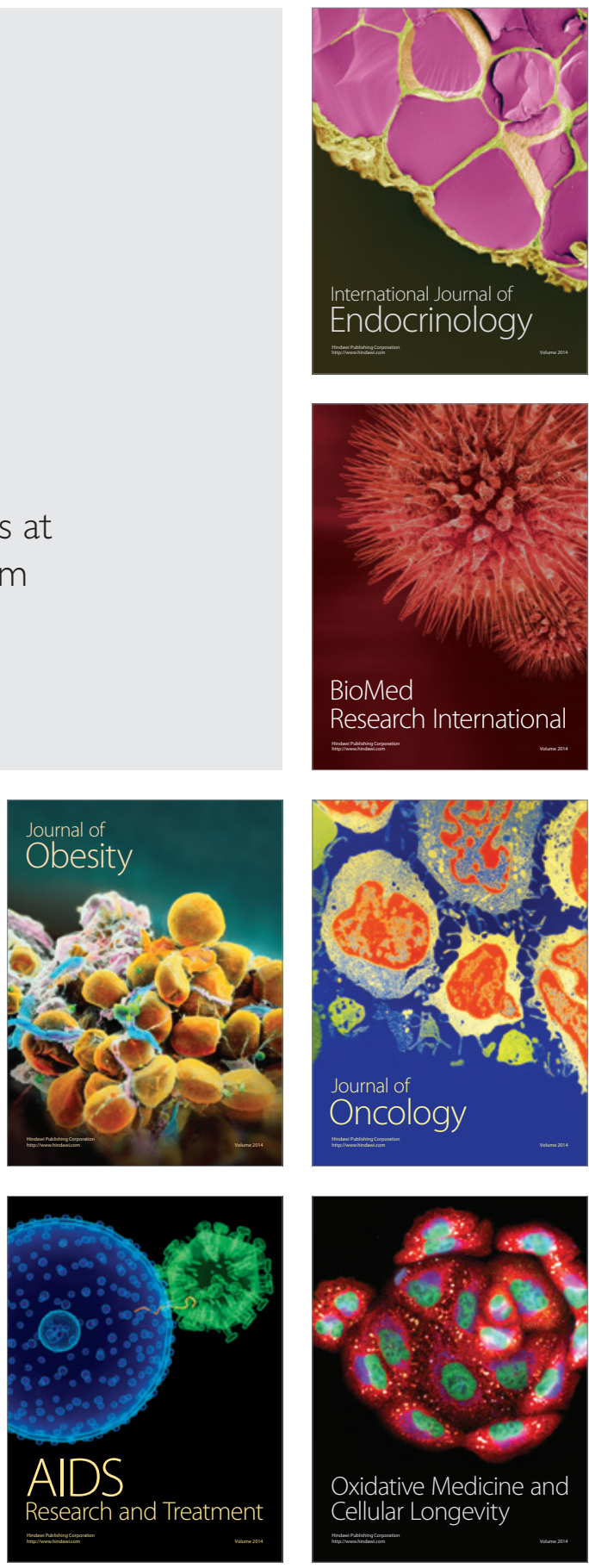